\title{
Several Technical Considerations for Taking the (Paper-and-Pencil-Based) TOEFL Test ${ }^{* 1}$
}

\author{
Gunadi Harry Sulistyo \\ State University of Malang
}

\begin{abstract}
The present article aims at presenting several points-commonly not realized by potential TOEFL test takers--that may be utilized to take the paper-and-pencil TOEFL. To these ends, several topics will be presented covering mainly the test format and the scoring scheme. It is under these topics that several technical strategies are discussed with the perspectives on successful paperbased TOEFL test taking.
\end{abstract}

Key words: paper-based, TOEFL, strategies

The data documented by Community Service Unit - a task force in the Department - indicate that the evidence in the English proficiency as reflected by the TOEFL scores has been increasingly needed by not only fresh university graduates but also senior high school students. The figures on those wishing to take the equivalent TOEFL test in the paper-andpencil format show the increase reaching at about $90 \%$ every year. (CSU Official Documents 2001). Further observations, however, reveal that almost $70 \%$ of those taking the test can gain equivalent scores below 400 points at the scale of the paper-and-pencil TOEFL test. This information scems to be understandable considering that most of the test takers had, if any, limited training in coping with the test problems in the TOEFL format.

1 This article is a modified version of a paper presented at a one-day seminar on

"Computer-Based TOEFL: Concepts and Strategies" held on 26 May 2001 at

State University of Malang 
Interviews held at random with those test takers lead to the conclusion that at least they are posed with two main archetypal problems in their attempts to complete the TOEFL test. These are language related problems and unfamiliarity with the test format. Although these two types of problems may interfere partially, it is quite often the case that they come up simultaneously. The first type of problems language related ones revolves around the test takers' constraints of their knowledge and skills in English. These may include a shaky mastery of the grammatical items tested, a limited stock of vocabulary presented in the test, and their inherent insensitiveness to the naturalness of English use. The second type of problems, on the other hand, is generally centered upon the absence of strategies to cope with the test problems successfully when they are exposed to the format in the TOEFL test. As a result, they apply approximately similar strategies to completing different sub tests of the TOEFL test. In other words, they perform test items just because they have to under the constraints of systematic tactics to succeed the test. Of the two types of problems, however, the latter is less realized by the prospective test takers; as a result, they confidently believe that preparedness with language aspects is sufficient for them to take the TOEFL test. Though some are eventually successful with the right scores of achievement, many are disempowered and fail in disappointment and disbelief.

This paper is an attempt made to uncover several non language aspects several technical points related with the TOEFL test, especially the paper-and-pencil format commonly not considered by potential test takers of the TOEFL test. In some parts, however, language related issues will be touched on. The purpose of the paper is not to provide the prospective test takers with a foxy scheme to win the TOEFL test nor is it 'to go too far in small'. Rather, it presents several facts of opening, which is based on teaching experiences, 'to go past, where possible, the eye of the needle'. To this end, several subtopics will be presented in the order that follows: on the test book and the answer sheet, sections of each sub test, time allocation, scoring: who cares? and a.o.b. Finally the paper is concluded with a brief remark.

\section{ON THE TEST BOOK AND THE ANSWER SHEET}

The paper-and-pencil format of the TOEFL test normally consists of two separate articles. These are the test book and the answer sheet. The test book contains test items to which the test takers must attend and respond. The answer sheet is the paper in which the test taker must 'write' down the answer.

As with the test book, there are several steps of 'rituals' a test taker needs to exercise carefully, two of which needs considering. When the time to begin the test is rung, first, it is advisable to check the number of the pages to see if any of the pages is missing, or any of the test questions in the page is not printed clearly or missing (though normally this hardly happens). Incomplete pages, if any, of the test book should be reported immediately to the proctor on duty for a change of the complete one. Then, read the directions in each section very carefully. Also, it is important for a test taker to observe very carefully the sample questions following each direction. These sample questions show how the items must be completed. Simply, a test taker needs to familiarize themselves with the way the test questions are answered (See Appendix 1 for several samples of directions in each section and their associated practice questions).

Concerning the answer sheet, a test taker needs to examine these things carefully. The TOEFL test is of a multiple-choice type with four answer choices (A, B, C, and D) for each question, the answering of which is darkening the letter in the oval, which corresponds to the intended answer. As the scoring is mechanical, that is it is computerized, so, make sure that an appropriate lead pencil, normally $2 \mathrm{~B}$ black lead pencils, is used. Also, watch for unnecessary mistakes such as erasing unnecessary marks that causes the answer sheet to be torn or damaged, or unnecessarily twisting and pressing out of the shape of the answer sheet. This may cause inability of the scoring machine to read the intended answer choice.

Next, careful marking of the answer on the answer sheet also needs to be exercised. The paper-and-pencil TOEFL has two versions of the answer sheet horizontal and vertical. Only one version is used on a testing date.

Incorrect marking of the letter in the oval potentially puts a test taker 
at a loss of a valuable scoring point! Finally, a careful skipping is equally important. When a number is skipped due to a reason, for example a hesitation in answering the number, a test taker needs to be sure that s/he moves to correct row of the oval for the next question to be answered. Skipping an answer wrongly can lead to an unnecessary loss!

\section{SECTIONS OF EACH SUBTEST}

As a test battery of English proficiency, the TOEFL test consists of subtests, which are compartmentalized as Section I, Section II, Section III, and Section IV. These subtests are listening comprehension, structure and written expression, reading comprehension, and test of written English accordingly. As has been mentioned previously, these subtests, except test of written English, are in the multiple-choice format with four answer choices. The test of written English, however, involves a test taker to write a piece of composition. In general, the subtests require a test taker to demonstrate 'passive and receptive' language behaviors, in that a test taker of the TOEFL test is to understand North American English.

What is the purpose of each subtest? Each subtest has different goals. The listening comprehension subtest measures the ability to understand English as it is spoken in North America. The next section, structure and written expression, elicits a test taker's ability to recognize language that is appropriate for standard written English. The third section, reading comprehension, measures nontechnical reading matter. The last section, test of written English, as its name suggests, measures the ability to write in English on an assigned topic.

Each subtest has different parts with different functions. These parts are intended to pick out a test taker's language ability using different testing methods as the stimulus in the stem. These methods imply levels of ability, ranging form a simple to a more complex one. Earlier parts have the function to examine simple levels of language ability; whereas the later ones are intended to dig into the test taker's more complex language abilities. 'Test tricks' are frequently put in these parts on purpose. Therefore, in order to be an 'old dog' that will not be easily distracted by 'new test tricks' of the test, a test taker needs to learn the secret of the tricks so that s/he will be equipped with effective and efficient strategies to cope with the TOEFL test questions successfully. What follows is a brief account of parts on each subtest.

The listening comprehension section, Section I, generally employs three parts Part A, Part B, and Part C. The following is a brief description of each part in the section. Part A tests the test taker's ability to comprehend specific intended messages at the sentence level. This can take either a monologue or a dialog presented in a short conversation or talk. The conversation is then followed by a question. In this format one short conversation or talk is intended for one question. Consider the following tape script typically used for the monologue and the dialog format with their corresponding questions.

\section{The Monologue Format}

Monologue Script: Mark is supposed to get to work by 7:30, but he was forty-five minutes late this morning because he overslept.

Question: What time did Mark arrive at his office?

Answer choices: A. Mark arrived at 7:30

B. Mark arrived at $7: 45$

C. Mark arrived at $8: 15$

D. Mark arrived at $8: 45$

\section{The Dialog Format}

Dialog Script:

(man) : Oh. I forgot the lettuce. Start unloading the cart and I'll get it.

(woman) : Pick up a few tomatoes too.

(third voice): Where does the conversation probably take place?

Answer choices: A. In the yard
B. In a grocery store
C. In a restaurant
D. In a library

When a sentence level comprehension is tested, it may test the use of certain vocabulary items in a sentence or, relationships of ideas presented in a compound or a complex sentence. The situation used in the 
monologue or the dialog includes different contexts. It is in these areas that the tricks are inserted. The most frequently asked questions include aspects of places and computations.

Unlike Part A, Part B tests a test taker's beyond-sentence-level comprehension. The format used is a longer form of dialogs or conversations. Following the dialogs or conversations, several questions, normally three or four, are asked about the dialogs or conversations. The topics of the dialogs or conversations vary, including a wide range of differing social contexts such as a trip to a place, finding an accommodation, a consultation with a lecturer or a physician, or a shop conversation between a shop assistant and a buyer. What follows is a set of further examples of test questions normally used in Part B.

(man) : Are you ready for "The Big Apple"?

(woman) : Excuse me?

(man) : You know, New York City. You are going to New York City with us, aren't you? I wanted to show everybody around my old neighborhood.

(woman) : Oh... sure! I wouldn't miss it--especially when the tour guide is a native New Yorker.

(man) : I thought we could start at the Museum of Modern Art. Right now there is an exhibit on twentieth-century American painters.

(woman) : Fine with me... but what were you saying about ... a big apple?

(man) : "The Big Apple." It's a nick name for New York. I think I heard once that is started with jazz musicians in the 20 's.

(woman) : Oh

(man) : Whenever they played a concert in a city, they called that city an "apple". In those days, New York was the biggest city in the country, so they called it "The Big Apple."

(woman) : Hey, I have an idea! Let's go to a jazz club while we're there. (man) : Sounds good.

Questions

(narrator) : What is the man planning to see?

1. (A) An art exhibit

(B) Broadway play

(C) A modern dance production

(D) An opera

(narrator) : What can be inferred about the man?

2. (A) He is a jazz musician

(B) He wants to join the woman's club

(C) $\mathrm{He}$ is in the twenties

(D) He was born in New York

Upon listening to a dialog or conversation played, a test taker needs to immediately recognize and grasp contexts used in the dialogs of conversations. This can be drawn, by listening carefully to the text, from the overt use of specialized vocabulary items. These items then can be used as clues to probe for further information packed explicitly or implicitly in the text.

Another aspect a test taker needs to consider and to master is the recognition of the language functions or registers used by a speaker in the dialog or conversation. A statement, for example, may have the function as a reminder. Consider the statement that follows. "Sir, it's 8:30." spoken by a student in a class to a teacher. The statement does not mean that the teacher does not have a watch at which he can see the time. Also, a question does not always mean questioning such as in this "Beleven, are you with me?" addressed by a teacher in an angry tone to a student sitting at the back not listening to the teacher's explanation attentively.

Another aspect important for a test taker to consider is the rhetoric structure or the organization of the dialog or the conversation. A dialog may be developed using different ways. Is it evolved around the descriptive, expository, or the argumentative mode of discourse? Since each of these types of organization has a different composition, therefore, recognition of the rhetoric text structure also needs considering. 
Part C, the last part in the listening comprehension section, tests a test taker's beyond-sentence-level comprehension. The format used is a longer form of monologue, which can be a mini lecture or a short talk on a certain subject. Following the monologue, several questions, normally three or four, are asked about the talk. Just like Part B, the topics of the talks in Part $\mathrm{C}$ are also varied, including a wide range of differing social contexts as the sample below.

\section{Narrator:}

Today's discussion is about a common animal reaction--the yawn. The dictionary defines a yawn as "an involuntary reaction to fatigue or boredom." That's certainly true for human yawns, but not necessarily for animal yawns. The same action can have quite different meanings in different species.

For example, some animals yawn to intimidate intruders on their territory. Fish and lizards are examples of this. Hippos use yawns when they want to settle a quarrel. Observers have seen two hippos yawn at each other for as long as two hours before they stop quarreling.

As for social animals like baboons or lions--they yawn to establish the pecking order within social groups, and lions often yawn to calm social tensions. Sometimes these animals yawn for a strictly physiological reason--which is to increase oxygen levels. And curiously enough, when they yawn for a physical reason like that, they do what humans do--they try to stifle the yawn by looking away or by covering their mouths.

(narrator) : What is the speaker's main point?

1. (A) Animals yawn for a number of reasons

(B) Yawning results only from fatigue or boredom

(C) Human yawns are the same as those of other animals

(D) Only social animals yawn

(narrator) : According to the speaker, when are hippos likely to yawn?

2. (A) When they are swimming
(B) When they are quarreling

(C) When they are socializing

(D) When they are eating

Similar strategies to tackle the test questions asked in Part B seem to be applicable to Part $C$. That is to say, first, a test taker needs to immediately recognize and grasp contexts used in the talks. Next, a test taker also needs to recognize the rhetoric structure or the organization of the dialog or the conversation.

For all parts, Part A, Part B, and Part C, another handy strategy that may be used by a test taker is reading the answer options for all numbers for the corresponding monologues, dialogs or conversations, and talks quickly so as to hold a general idea of the context employed in the text.

Questions frequently asked in Part B and encompass two aspects: explicit and implicit information. The former is related with at least two areas: global understanding of dialogs or talks and specific or detailed information whereas the latter is concerned with inferential information. There are also other aspects other than these frequently asked in Part C. A test taker, therefore, needs to know whether a question is oriented to the former or the latter. To cater for the skill, several forms of exercises need to be developed to equip the test taker with the working skill in skimming, scanning, or inferring.

Section II or Structure and Written Expression has two parts, Part I and Part II. This section in general is to measure the test taker's ability to recognize language appropriate for standard written English. In particular, Part I is designed to measure the test taker's knowledge in the areas of English structure whereas Part II is developed to qualify the test taker's knowledge of English as used in written expression.

Parts I and II employ different test formats. The test format typically used in Part I of Section II is an incomplete sentence as the stem and four answer choices below the stem. What follows is a typical format normally used in Part I

George belongs to the

A. class of the upper middle

B. upper middle class 
C. class from the center up

D. high medium class

Unlike Part I, Part II uses an error recognition format in which a test taker is to spot a grammatical error contained in a sentence. The erroneous part is underlined with the letters A, B, C, and D below the part. Consider the sample test question in Part II below.

The most difficult books to understand that this author has written A

they are the most widely read.

C

Both parts, Part I and Part II, basically dictate that first of all a test taker be highly sensitive to two aspects: accuracy in grammatical forms and appropriateness in the style of grammatical uses. Both aspects require the test taker to have a solid mastery and knowledge of important areas in the English grammatical structures as well as in the language style as used in standard written English. These may include the areas of parallelism; incorrect verb tenses, aspects, and forms; concord: subject-verb and nounpronoun; modifiers using the wrong word order; and other grammatical areas. It follows then that once a test taker faces a test question in a real test question, $\mathrm{s} /$ he must be immediately able to recognize the possible area of grammatical items being tested. If a test taker has not reached this kind of grammatical sensitivity, s/he might still need to learn the grammatical areas more intensively, which is then proceeded with extensive exercises on the areas. Finally, the most important point a test taker must remember is that a test question is always presented in the form of a sentence, be it simple, compound, or complex. This is understandable because in standard written English only complete sentences are conventionally acceptable. As a consequence, the stem containing a particular grammatical item being tested never appears in the form of phrases: long or short or dependent clauses. Thus, a test taker should also master thoroughly the concept and the anatomy of 'phrase', 'clause', and 'sentence'.

To face Part I, several strategies may be exercised. These can be through exploring the stems or exploring the options. If a stem is long, that is it has more than one clause or phrase, skip the parts that are deliberately used to distract the test taker's attention from the intended grammatical item being tested. Here is an example of a long stem:

Professor Bird decided, after many years of administering programs and supervising teachers,

The part, after many years of administering programs and supervising teachers, can be skipped so as simply to read Professor Byrd decided. This short reading of the stem certainly will simplify the process of matching the stem with the answer options that follow by for example focusing on the transitive verb decided in the stem, which needs an object of a noun, noun phrase, or a clause.

A rather similar strategy as is the one used in the listening comprehension section may be applied to completing Part I of Structure and Written Expression. This strategy is exploring the answer options briefly before observing the stem. Normally the options contain a particular grammatical area being tested, which is frequently repeated in all options. The advantage of this strategy is therefore a quick recognition of the grammatical aspect being tested. Consider the following answer options, which have been left out from their original test item:
A. whale is only the
B. only the whale is
$\mathrm{C}$. is the whale only
D. only whale is the

What is being tested? A quick look at these options simply leads to the use of a grammatical point 'only'; especially the word order in which 'only' is used. Just by looking at the options, the possible correct one is option B. (Why?). And this choice seems to work absolutely well. Now, try to put the option in the original stem:

Throughout the animal kingdom, only the whale is bigger than the elephant.

When appropriateness in the style of grammatical uses is being tested 
in Part I, sometimes the strategy of examining accuracy of grammatical form in the options does not always work perfectly well. In this case what frequently happens is that all options can be grammatically correct with no change in the intended meaning. Therefore, spotting correctness can be frustrating. A key to solve this problem can be carried out by looking at the naturalness of the expression, which is normally obvious from simplicity in the grammatical forms used and straightforwardness in the expression. Put simply, flowery expressions are as far as possible normally avoided in the standard written form.

Now, consider two sets of answer options in the following section

\section{A. talked all they wanted \\ B. make lots of expressions \\ C. speak freely \\ D. talk with their minds open}

\section{A. another fifty}

B the same amount also

C. one other fifty dollars

D. more fifty dollars

Can you guess the correct option just by looking at the simplicity of the grammatical forms and the straightforwardness in the expression used?

Unlike Part I, Part II seems to need different strategies to cope with. To deal with Part II, a test taker has a need for another strategy besides knowledge of grammatical rules. Part II involves error recognition, that is the process of detecting a deviation in the rules that will not be acceptable in standard written English. As such it requires the test taker to employ more sensitivity to the accurate use of grammatical rules.

In facing Part II, a test taker normally will rely on 'translating' for the sentential meaning of the forms tested. This seems to be inevitable. As a result, she/he fails to evidence the presence of the grammatical deviations in the sentence. This situation potentially worsens when the grammatical item being tested includes 'little words' such as articles, prepositions, auxiliary, or conjunctions. This follows that one strategy that can be used is avoiding the translation approach. It should be noted securely that Part II does not test 'communication of meaning' rather 'sensitivity toward rule usage'. Take a look at the following test item: $\frac{\text { This }}{\mathrm{A}}$ new theory $\frac{\text { was }}{\mathrm{B}}$ very $\frac{\text { well }}{\mathrm{C}}$ received in the past few weeks.

When the sentence above is approached using 'translation', it looks right with the meaning that can be created. As a result, it looks as if the sentence bears no grammatical error. The translation approach has distracted the test taker's attention from spotting the error. Thus, a simple test item becomes a real problem to the test taker, resulting in consuming more time to solve. A closer and sensitive look at the item actually can help.

Section III, Reading Comprehension, is like Section I Listening Comprehension in that both are in general designed to measure both sentential comprehension and beyond-sentence comprehension. Sentential comprehension may involve the testing of vocabulary items in context (Recently, however, there has been a tendency to put vocabulary tests as a part of paragraph comprehension). Beyond-sentence comprehension revolves around textual comprehension of a paragraph and that of an essay. Section III, just like Section I, may consist of two parts: Part I and Part II. The difference between Section I and Section III, however, lies in the medium: Section I involves auditory channels; Section III requires visual modes. In addition to this, the strategies to tackle the questions in Section I may be workable partially for the problems in Section III

An important technical strategy seemingly applicable to tackling problems in the reading comprehension section may rest on the analytical ability of the test taker towards the text. A test taker thus needs to recognize the structure of a paragraph (for Part I) as well as that of an essay (for Part II). Thus, at the level of paragraph structure, for example, a test taker needs to know rhetoric aspects related to 'topic sentence', 'supporting sentence', and cohesive devices. In short, mapping the text structure would be a functional device for the test taker to work with Section III. The advantage is that a test taker does not necessarily read the whole text. S/he can focus on the 'frame' that constitutes a paragraph or essay, thus saving reading time.

Another essential strategy is that the test taker necessarily has a need of rhetoric patterns on which a paragraph or an essay is developed. A text may be developed on a descriptive, expository, or an argumentative basis. 
Each of these texts has different tones viewed from the writer's point of view.

Section IV, Test of Written English, is tested on certain test dates only. Therefore, this test, unlike the first three subtests, is not always included in a TOEFL test administration. Unlike the other subtests, this writing test consists only of one test prompt that requires a test taker to write a piece of essay composition of about 250-300 words on a topic out of the provided list. The rhetoric mode of writing assessed is normally expository or argumentative.

The main focus of the assessment lies on the test taker's ability to organize ideas including how well a test taker presents details, examples, and reasons to support the main idea stated in the topic sentence or thesis statement. The key strategy seems to be that a test taker needs to know rhetoric aspects related to 'topic sentence', 'supporting sentence', and cohesive devices. Also, s/he needs to know how an expository or argumentative piece of essay composition is developed; and equally important is that $\mathrm{s} /$ he needs to practice writing under time constraints.

Several points discussed in the previous sections are concerned with contents, that is the test taker's language proficiency, the sections that follow, however, will be focussed on several non language-related aspects. While the previous sections discuss sensitivity to accuracy of forms, the sections below deal with technical matters.

\section{TIME ALLOCATION}

The time for each subtest is allocated in different portions. The table that follows presents the time allocated for each subtest.

Table 1: Time Allocation in Each Section

\begin{tabular}{|l|l|c|c|}
\hline No. & \multicolumn{1}{|c|}{ Subtest } & $\begin{array}{c}\text { Number of } \\
\text { Items }\end{array}$ & $\begin{array}{c}\text { Time in } \\
\text { Minutes }\end{array}$ \\
\hline 1 & Section I: Listening Comprehension & 50 & 50 \\
2 & Section II: Structure and Written Expression & 40 & 25 \\
3 & Section III: Reading Comprehension & 60 & 45 \\
4 & Section IV: Test of Written English & - & 30 \\
\hline \multicolumn{2}{|c|}{ Total } & 150 & 150 \\
\hline
\end{tabular}

Table 1 above shows that to complete all four sections in the TOEFL test, a test taker is required to spend totally 150 minutes or equivalent to 2 hours and 30 minutes (It should be noted that the administration of the first three sections: Section I, Section II, and Section III are non-stop, which is then continued with Section IV after a short break of about 15 minutes).

The question that comes up then is: how will a test taker spend the time allocated? The time for each section is strict in that if a test taker can finish a section before the time, s/he is not allowed to continue the section that comes next. This means that, excluding Test of Written English, in Listening Comprehension simply a test taker is provided equally with one minute to complete one item; in Structure and Written Expression the time provided for completing one item is even shorter approximately 30 seconds, so is the time in Reading Comprehension: a test taker is to spend approximately 45 seconds for one item. In short, it can be said that roughly to complete one test problem, a test taker is to spend about 45 second!

The next question that arises is what can a test taker perform with 45 seconds to accomplish a test problem? The answer is probably this. At least there will be three activities a test taker can make. These are reading (the test question and/or the answer options), determining the answer, and darkening the oval thoroughly. If each of these activities consumes approximately the same amount of time, it will mean that one activity needs equally 15 seconds to complete! What does this mean? The time provided is short! The test taker is strictly constrained by the time in the TOEFL test! The implication is then that, first, there is no point to spend disproportionate time on one item, and next, there is a compelling need to settle one test question promptly. In short, promptness seems to be worth considering!

With regard to the time constraint described previously, several points of caution, however, necessitate a test taker's noteworthy attention. First, settling the test questions quickly is not always fruitful if the correctness factor is neglected. Similarly, correctness leaving the factor of speed is also not always fruitful. Therefore, then, there should be a proportionate balance between correctness and speed. How can it be achieved? Prior to taking the TOEFL test, a test taker needs to think about 
sufficient treatment in the form of special training carefully designed for the purpose.

\section{SCORING: WHO CARES?}

Another aspect, which is frequently not reckoned thoughtfully by a test taker, is scoring. Probably what a test taker is commonly aware of is that scoring is based on the correct answer. This is not wrong in that there is one-to-one scoring: one correct answer is valued as one point score. But how is scoring treated? Actually there is a systematic procedure to follow to come up to the final TOEFL score. However, a simple step can be illustrated as follows: raw scores obtained in each section (which are necessarily the correct answers) are transformed to 'converted' scores. These converted scores in each section are then added up altogether, the result of which is further multiplied by $10 / 3$ to yield the test taker's TOEFL score. Decimal values are either rounded up (for the decimal values greater than .66 ) or rounded down (for the decimal values greater than .33) to the nearest whole number.

What is more relevant for this present discussion seems to be examining the converted score range table as follows:

Table 2: Converted Score Range Table (Adapted from Undertsanding TOEFL, 1989:17)

\begin{tabular}{|c|c|c|c|}
\hline $\begin{array}{c}\text { Number-Right } \\
\text { Score Range }\end{array}$ & Section 1 & Section 2 & Section 3 \\
\hline $57-58$ & - & - & $66-67$ \\
\hline $54-56$ & - & - & $63-65$ \\
\hline $51-53$ & - & - & $60-62$ \\
\hline $48-50$ & $64-68$ & - & $58-59$ \\
\hline $45-47$ & $61-63$ & - & $55-57$ \\
\hline $42-44$ & $58-60$ & - & $53-55$ \\
\hline $39-41$ & $56-57$ & - & $52-53$ \\
\hline $36-38$ & $53-55$ & $62-68$ & $50-51$ \\
\hline $33-35$ & $51-53$ & $58-60$ & $48-49$ \\
\hline $30-32$ & $49-51$ & $54-56$ & $46-47$ \\
\hline $27-29$ & $48-49$ & $50-53$ & $44-45$ \\
\hline
\end{tabular}

\begin{tabular}{|c|c|c|c|}
\hline $24-29$ & $46-47$ & $47-49$ & $41-43$ \\
\hline $21-23$ & $44-45$ & $44-46$ & $39-41$ \\
\hline$\ldots$ & $\ldots$ & $\ldots$ & $\ldots$ \\
\hline $6-8$ & $30-32$ & $27-30$ & $25-27$ \\
\hline $3-5$ & $28-29$ & $24-26$ & $23-24$ \\
\hline $0-2$ & $25-27$ & $20-22$ & $20-22$ \\
\hline
\end{tabular}

The table shows that first the highest scores a test taker can obtain in each section (Section 1, Section 2, and Section 3) are 68, 68, and 67 respectively, which makes a TOEFL score of 676.66 , or rounded up to make 677; secondly, the lowest scores that are obtainable in each section (Section 1, Section 2, and Section 3) are 25, 20, and 20 respectively, which makes a TOEFL score of 216.66 , or rounded up to make 217. Finally, for raw scores smaller than 24 points, the same raw score may have different values on their converted score, with the highest for Section 1 followed by that for Section 2 and the lowest for Section 3. For example, a raw score of 8 points will be converted to 32 points in Section 1,30 points in Section 2, and 27 points in Section 3. For the same raw scores greater than 24 points, however, their corresponding converted scores which are highest are for Section 2, followed by those for Section 1 , and finally those for Section 3. Thus, for example, a raw score of 30 points will be converted to 49 points in Section 1, 54 points in Section 2, and 46 points in Section 3.

The information described previously implies several important points. First, considering that there are weighting differences in scoring for different sections, a test taker can devise this feature as a strategy in compensating for scores missed in a section. For example, as Section I Listening Comprehension--is considered the hardest part by many, a test taker may try better to make the least mistakes as far as possible in Section 2 or Section 3. Next, a test taker attending the test, but accomplishing no single item, or missing all items, will get a TOEFL score of 217 points. This score will be an important point to start. Thus, to reach a score of 450 points, for example, a test taker needs to have another 233 points. A part from his/her language ability, how can s/he 'collect' additional points to meet the target. One possible way through which s/he can go is by making use of one inherent problem attributed to by a 
multiple-choice format. A blind guessing on the multiple-choice format with four options will theoretically yield at least $25 \%$ of correct answers. While there is no penalty applied to the wrong answers in the TOEFL scoring, this weakness of the multiple-choice format will be a good benefit for the test taker if s/he can luckily devise the weakness.

\section{A.O.B.}

There are some other points worth addressing. In the first place, the paper-and-pencil TOEFL test, unlike the computer-based format, is nonadaptive. The level of the difficulty of the items in general is moderate. Also, some items may test indirect and non-communication aspect of English. The test questions, mostly, however, examine the test taker's sensitiveness to accuracy of forms. A test taker's may find some items 'trivial' in terms of language components tested such as 'articles', 'prepositions', or 'verb forms' which sometimes cause 'local errors' and do not necessarily hinder communication. Finally, several items or texts have culturally bound expressions, which sometimes makes it difficult for a non-native to understand the meaning.

\section{A BRIEF REMARK: CONCLUSION AND SUGGESTION}

Sensitivity to accurate forms is important. Rate in accomplishing is also vital for a successful TOEFL test taking. These non language-related aspects are necessary to be aware of; however, these should not be too overemphasized. A test is a test in its nature. With language use, however, the real test is when one is to be linguistically functional that is able to listen, speak, read, and to write, when they are to live in society. To communicate using language, one will depend on their language abilities to understand and be understood. Therefore, solid mastery of linguistic abilities needs to be prioritized. Nevertheless, the strategies discussed in this paper, hopefully, will be useful for the prospective test taker of the TOEFL test. Finally, be sufficiently prepared with strategies if you are serious about taking the TOEFL test!

\section{REFERENCES}

Alderson, J.C. 2000. Assessing Reading. Cambridge: Cambridge University Press.

Bachman, L.F. and A.S. Palmer. 1996. Language Testing in Practice. Oxford: Oxford University Press.

CSU. 1999. Materials for the TOEFL Preparation. Malang: Community Service Unit, English Department, FPBS-IKIP MALANG

Pyle, M.A. 1992. Advanced Practice for the TOEFL. Lincoln: Cliffs, Inc.

Sulistyo, G.H. 1996. Global and Local Errors: Perspectives on Language Testing. Science. No.34 June 1996 pp. 54-65.

Educational Testing Service. 1999. TOEFL Tips: Preparing Students for the Computer-Based Testing. Princeton: Educational Testing Service

Educational Testing Service. 1999. TOEFL 1999-2000 Information Bulletin for Computer-Based Testing. Princeton: Educational Testing Service.

Educational Testing Service. 1999. TOEFL 1999-2000 Information Bulletin for Supplemental

TOEFL Administrations. 1999. Princeton: Educational Testing Service. Understanding TOEFL. Princeton: Educational Testing Service. 